\title{
A randomized, placebo-controlled, four-period crossover, definitive QT study of the effects of APF530 exposure, high-dose intravenous granisetron, and moxifloxacin on QTc prolongation
}

\author{
This article was published in the following Dove Press journal: \\ Cancer Management and Research \\ 26 March 2014 \\ Number of times this article has been viewed
}

Jay W Mason'

Thomas E Moon ${ }^{2}$

Erin O'Boyle ${ }^{3}$

Albert Dietz ${ }^{4}$

'Department of Medicine, University of Utah, Salt Lake City, UT, ${ }^{2}$ Tarizona eHealth Services, Inc., San Carlos, CA, ${ }^{3}$ AP Pharma, Redwood City, CA, ${ }^{4}$ Spaulding Clinical Research, West Bend, WI, USA
Correspondence: Jay W Mason

105 Londonderry Court,

Reno, NV 895II, USA

$\mathrm{Tel}+\mathrm{I} 7758499910$

Fax+l 7758499910

Email jwm@jaywmason.com
Background: Regulatory concern about potential QT-interval prolongation by serotoninreceptor antagonist antiemetics prompted product-label changes. The first-generation serotoninreceptor antagonist granisetron is available in oral (PO), intravenous (IV), and transdermal formulations. APF530 is a formulation that provides sustained release of granisetron when administered as a single subcutaneous (SC) injection. The Phase I study reported here evaluated effects of APF530 on electrocardiographic intervals.

Methods: This single-site, double-blind, placebo-controlled, four-period crossover trial randomized healthy men and women to receive varying sequences of APF530 $1 \mathrm{~g} \mathrm{SC}$, granisetron $50 \mu \mathrm{g} / \mathrm{kg} \mathrm{IV}$, moxifloxacin $400 \mathrm{mg}$ PO, and placebo. Subjects were assessed for 49 hours after each treatment. The primary objective was to evaluate differences between baseline-adjusted, heart rate-corrected QT-interval change using the Fridericia rate correction (dQTcF) for APF530 $1 \mathrm{~g}$ $\mathrm{SC}$ and placebo. Electrocardiograms were performed at various times throughout the assessment period. Pharmacokinetics and safety were evaluated.

Results: The upper one-sided 95\% confidence interval (CI) for mean baseline-adjusted dQTcF at each post-dose time point between APF530 and placebo excluded $10 \mathrm{~ms}$, indicating that APF530 $1 \mathrm{~g} \mathrm{SC}$ had no clinically significant effect on QTcF. Maximum observed QTcF change was 4.15 $\mathrm{ms}(90 \% \mathrm{CI}, 0.94$ to 7.36$)$ at Hour 3. No clinically significant changes in other electrocardiogram intervals were observed. APF530 SC pharmacokinetics were as expected, with slow absorption (maximum plasma concentration $35.8 \mathrm{ng} / \mathrm{mL}$, median time to maximum plasma concentration 11.1 hours) and slow elimination (mean half-life 18.6 hours; systemic clearance $20.2 \mathrm{~L} /$ hour) of granisetron versus the expected early peak concentration and elimination of granisetron IV. APF530 SC was well tolerated. Adverse events, most commonly constipation and SC injectionsite reactions, were generally mild and quickly resolved.

Conclusion: APF530 $1 \mathrm{~g}$ SC did not induce clinically significant QTcF interval prolongation or changes in the other electrocardiogram intervals, and was well tolerated at twice the recommended dose.

Keywords: APF530, chemotherapy-induced nausea and vomiting, extended-release, granisetron, subcutaneous, QTc interval

\section{Introduction}

Patients with cancer who are receiving chemotherapy frequently experience chemotherapy-induced nausea and vomiting (CINV), which can significantly affect both quality of life and adherence to chemotherapy because of dose reduction and treatment delay, unless effective prophylaxis is administered. ${ }^{1}$ The introduction of 
first-generation serotonin $\left(5-\mathrm{HT}_{3}\right)$-receptor antagonists in the 1990s (ondansetron, granisetron, dolasetron) provided a considerable advance in the prevention of CINV. ${ }^{2}$ Current guidelines for the prevention of CINV base their recommendations primarily on the emetogenicity of the chemotherapy regimens (low, moderate, high) and the type of emesis (acute, delayed, anticipatory, breakthrough). ${ }^{3-5}$ Three classes of antiemetics are presently used alone or in combination to prevent CINV: 5- $\mathrm{HT}_{3}$-receptor antagonists (granisetron, ondansetron, dolasetron [oral only], palonosetron), the corticosteroid dexamethasone, and neurokinin 1 (NK-1)-receptor antagonists (aprepitant, fosaprepitant). ${ }^{3-5}$ Although $5-\mathrm{HT}_{3}$ antagonists are effective and have been used extensively in the clinic for many years, preclinical and clinical studies have shown that some $5-\mathrm{HT}_{3}$ antagonists may cause adverse cardiac effects, including heart rate-corrected QT (QTc)interval prolongation, which can lead to arrhythmias and sudden death, depending on the specific agent, the dose, and the route of administration. ${ }^{6}$

Labeling for some of the currently approved $5-\mathrm{HT}_{3}$ antagonists indicates the potential for cardiac adverse events (AEs), primarily prolongation of the QT interval but also other changes of electrocardiogram (ECG) intervals. ${ }^{7-12}$ In 2010 and 2011, the US Food and Drug Administration (FDA) required the withdrawal of intravenous (IV) dolasetron for the treatment of CINV due to cardiac safety concerns ${ }^{11,13}$ and expanded warnings in labeling regarding potential cardiac safety issues with ondansetron and granisetron. ${ }^{14,15}$ Subsequently, in 2012, the FDA requested the withdrawal of ondansetron $32 \mathrm{mg}$ IV for the treatment of CINV,, ${ }^{9,16}$ and the labeling was revised to reduce the IV dose to a maximum of $16 \mathrm{mg}$ per dose. Labeling for the second-generation $5-\mathrm{HT}_{3}$ antagonist palonosetron ${ }^{17}$ indicates the potential for cardiac safety issues, although the warning about QT-interval prolongation was removed from the prescribing information in 2008 .

Granisetron is currently available in IV, oral (PO), and transdermal formulations. Although small clinical trials with IV and PO granisetron ${ }^{18-23}$ have not found any significant changes in QT intervals, individual reports of QT prolongation have been published. ${ }^{7,8}$ A recent cardiac safety study of transdermal granisetron found no evidence of significant effects on QTc or other ECG variables. ${ }^{24}$

"APF530" (AP Pharma, Inc., Redwood City, CA, USA) is a long-acting polymer formulation of granisetron, composed of $2 \%$ granisetron and a vehicle of tri(ethylene)glycol poly(ortho ester) and methoxy poly(ethylene glycol). The design of this product enables a single subcutaneous (SC) injection to provide sustained release of therapeutic levels of granisetron over a 120 - to 168 -hour period. ${ }^{25}$ Because of the FDA requirement to conduct a thorough QT/QTc study on non-antiarrhythmic drugs (implemented in 2005), ${ }^{26}$ the Phase I trial reported here was conducted to undertake a detailed evaluation of the effects of APF530 on QTc and other ECG intervals in healthy human adults and to compare these effects with those of IV granisetron. To verify the assay's sensitivity, moxifloxacin hydrochloride, an agent known to cause QT prolongation, was used as a positive control.

\section{Methods \\ Study design and treatment}

This Phase I, single-site, double-blind, randomized, placebocontrolled, four-way crossover study examined the effect of APF530 1 g SC, granisetron $50 \mu \mathrm{g} / \mathrm{kg} \mathrm{IV}$, and moxifloxacin $400 \mathrm{mg}$ PO on the QT interval of healthy male and female subjects. The study was conducted in accordance with Good Clinical Practice E-6 Guidance ${ }^{27}$ and the Declaration of Helsinki. ${ }^{28}$ The final protocol was approved by the local independent ethics committee. Treatment groups were defined as follows: APF530 $1 \mathrm{~g} \mathrm{SC}$ (granisetron $20 \mathrm{mg} / 0.84$ $\mathrm{mL}$ plus matching IV and PO placebos; regimen A); granisetron IV $(50 \mu \mathrm{g} / \mathrm{kg}$ in $10 \mathrm{~mL}$ of $0.9 \%$ normal saline plus matching SC and PO placebos; regimen B); placebo (SC, IV, and PO placebos; regimen C); and moxifloxacin $400 \mathrm{mg}$ PO (plus matching SC and IV placebos; regimen D). The positive control (moxifloxacin) was included to meet FDA requirements that a study of the QT-prolonging effects of new drugs be performed and that, whenever possible, the study should include a positive control. After screening, eligible subjects were randomized 1:1:1:1 to one of four treatment sequences. Each treatment was administered once on Day 1, and the results were monitored for the subsequent 49 hours. The first three assigned treatments were followed by a 7-day washout period (Figure 1).

The primary objective of the study was to evaluate the effect of APF530 $1 \mathrm{~g} \mathrm{SC}$ (20 mg of granisetron) on change from baseline of the QTcF interval using the Fridericia ratecorrection method over 49 hours. The dose of APF530 was designed to achieve a mean maximum plasma concentration $\left(\mathrm{C}_{\max }\right)$ and area under the concentration-time curve (AUC) of granisetron in normal volunteers equivalent to that achieved by APF530 $500 \mathrm{mg} \mathrm{SC} \mathrm{(10} \mathrm{mg} \mathrm{of} \mathrm{granisetron)} \mathrm{administered} \mathrm{to}$ patients with cancer. Secondary objectives included evaluation of heart rate, PR interval, QRS interval, uncorrected QT interval, change in ST- and T-wave morphology, and categorical change in QTc and other ECG variables after administration of 


\section{First arm}

Day - 1: check-in

Days 1 and 2 PK and ECG time points

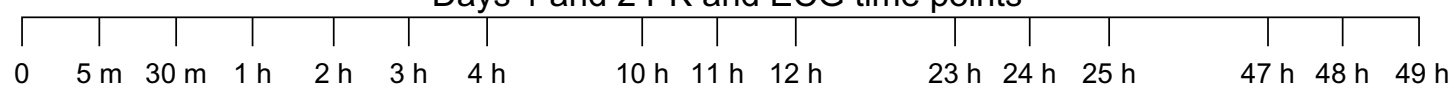

Days 3-9: washout

Second arm

Day - 10: check-in

Days 11 and 12 PK and ECG time points

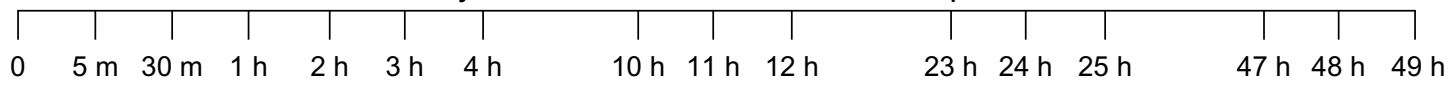

Days 13-19: washout

Third arm

Day - 20: check-in

Days 21 and 22 PK and ECG time points

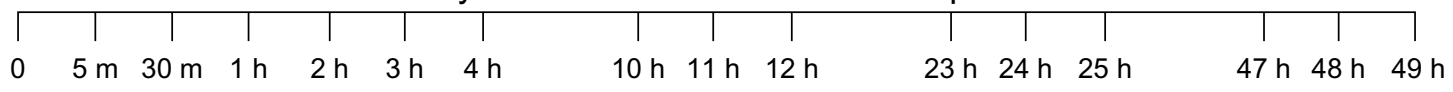

Days 23-29: washout

Fourth arm

Day - 30: check-in

Days 31 and 32 PK and ECG time points

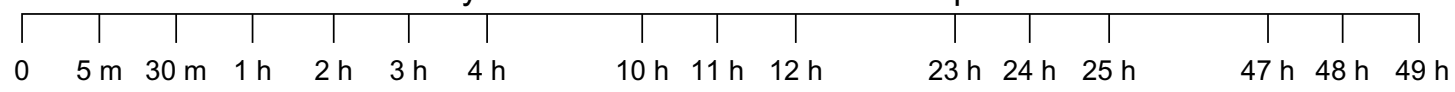

Days 32: discharge

Figure I Study design.

Abbreviations: ECG, electrocardiogram; PK, pharmacokinetics; m, minutes; h, hours.

APF530 $1 \mathrm{~g}$ SC compared with placebo. Correlation between QTcF change from baseline and plasma concentration was determined, as were safety (SC administration-site reactions) and assay sensitivity (using moxifloxacin as the active control). The dose of IV granisetron $(50 \mu \mathrm{g} / \mathrm{kg}$ ) was selected to achieve a mean $\mathrm{C}_{\text {max }}$ that was four-fold the mean $\mathrm{C}_{\max }$ of approximately $18 \mathrm{ng} / \mathrm{mL}$ observed in patients receiving the clinical dose of APF530 (500 mg SC), and was five times the recommended dose of $10 \mu \mathrm{g} / \mathrm{kg} .{ }^{8}$

\section{Subjects}

Eligible subjects were males and females between 18 and 50 years of age deemed to be in good health by a study physician.
Participants weighed at least $50 \mathrm{~kg}(110 \mathrm{lb})$, had a body mass index of between 18 and $32 \mathrm{mg} / \mathrm{m}^{2}$, and had all clinical laboratory evaluations within the reference range. Key exclusion criteria included participation in another trial within 30 days of screening; any condition impairing proper drug absorption; evidence or history of clinically significant allergic, cardiovascular, endocrine, hematologic, hepatic, gastrointestinal, neurologic, or psychiatric disease; having a first-degree relative with long QT syndrome or a family history of unexplained sudden death or unexplained syncope; abnormal ECG at screening indicating second- or thirddegree atrioventricular (AV) block, or one or more of the following: QRS >110 ms, change in QTc using the Bazett 
method $(\mathrm{QTcB})>470 \mathrm{~ms}$ for females or $450 \mathrm{~ms}$ for males, PR interval $>240 \mathrm{~ms}$, or any rhythm other than sinus rhythm interpreted by the investigator as being clinically significant. All subjects provided written informed consent.

\section{Assessments}

Each subject was assessed for 49 hours after each treatment was administered. Resting ECGs from 12-lead digital ECG recordings (Mortara X12+TM, Mortara Instrument, Milwaukee, WI, USA) were extracted from uninterrupted telemetry at predetermined time points. Three recordings were taken per time point, each approximately 1 minute apart. Time points for ECG sampling occurred on Days 1, 11, 21, and 31 before dosing, then at 5 and 30 minutes and 1 hour and 2, 3, 4, 10, 11, $12,23,24$, and 25 hours post-dose. ECGs were also undertaken on Days 2, 12, 22, and 32, at 47, 48, and 49 hours post-dose. ECG recordings from each subject were based on the same lead and read by the same blinded cardiologist throughout the study. Blood sampling for pharmacokinetic analysis occurred on the same days on which ECGs were obtained, immediately after ECG sampling. Safety and tolerability assessments consisted of evaluations of dose site, vital signs, physical examination, and clinical laboratory tests.

\section{Statistical methods}

Two study populations were predefined. Subjects included in the ECG analysis were those who received any study drug and had ECG data collected before dosing and at one or more post-dose time points. The pharmacokinetic analysis population included all subjects who received any study drug and had sufficient plasma concentration data to allow calculation of pharmacokinetic parameters. Continuous demographic and baseline characteristics were summarized using descriptive statistics, and frequency counts were tabulated for categorical demographic variables. Descriptive statistics were used to summarize ECG variables and corresponding changes from baseline of QT/QTc and other ECG variables by study dose group and time of measurement for each treatment.

The primary analysis of the primary endpoint was the baseline- and placebo-adjusted change in QTcF (ddQTcF) during treatment with APF530 using a mixed-effects model, and including terms for dose sequence, subjects within sequence, study drug (APF530 or placebo), study period, post-dose ECG assessment time point, study drug by postdose ECG time point interaction, and study period by postdose ECG time point interaction. An unstructured covariance model was used, and the mean and upper 95\% one-sided confidence interval $(\mathrm{CI})$ of ddQTcF during treatment with
APF530 were used to make the primary statistical assessment. If the upper $95 \%$ one-sided $\mathrm{CI}$ of ddQTcF at each post-dose time point excluded $10 \mathrm{~ms}$, then no clinically meaningful QTc interval prolongation was concluded.

A secondary analysis using the same model was carried out for the IV granisetron treatment. Additional secondary analyses were performed for each treatment for the ECG variables HR, PR, QRS, QT, and abnormal diagnostic statements.

A sensitivity analysis of the assay was conducted to determine the predicted mean difference (ddQTcF) and the associated lower 95\% one-sided CI across all subjects for moxifloxacin. The assay sensitivity of the study was validated if the lower $95 \%$ one-sided CI for ddQTcF was greater than $5 \mathrm{~ms}$ at a minimum of one of four time points after dosing (Hours 1, 2, 3, or 4).

Categorical analyses of QTcF were performed to determine the number and percentage of subjects, by treatment group, who met the following outlier criteria: QTc $>450 \mathrm{~ms},>480 \mathrm{~ms}$, and $>500 \mathrm{~ms}$; change of QTcF over pre-dose baseline $>30 \mathrm{~ms}$ and $>60 \mathrm{~ms}$ at any time point; and frequency of morphological findings compared with baseline.

Graphical and mixed-effects analyses were used to evaluate the relationship between plasma concentration of granisetron and dQTcF. Descriptive statistics were used to summarize pharmacokinetic data. Safety was assessed by AEs, which were summarized overall, by severity, and by relationship to study drug. Clinical laboratory data were analyzed using shift tables.

\section{Results Subject characteristics}

The study was completed at a single site between July and October 2011. A total of 56 subjects were enrolled in the trial, and 51 completed the study and were included in the primary analyses. Three subjects discontinued because of an $\mathrm{AE}$, one discontinued because of a protocol violation, and one discontinued by choice. Subject demographics and baseline characteristics are listed in Table 1.

\section{Electrocardiography}

The primary analysis was the ddQTcF during APF530 treatment. APF530 $1 \mathrm{~g}$ SC produced no clinically significant effect on QTcF. The maximum observed mean ddQTcF during treatment, occurring at Hour 3, was $4.15 \mathrm{~ms}$ (90\% CI, 0.94 to 7.36$)$. The maximum adjusted mean change using the mixed-effects model was $3.75 \mathrm{~ms}$ (90\% CI, 0.61 to 6.89$)$ (Figure 2A), also at Hour 3. The mean $\mathrm{C}_{\max }$ of granisetron administered as APF530 $1 \mathrm{~g} \mathrm{SC}$ was $35.8 \mathrm{ng} / \mathrm{mL}$. The linear 
Table I Subject demographics and baseline characteristics

\begin{tabular}{|c|c|c|c|c|c|}
\hline & \multicolumn{5}{|c|}{ Treatment sequence } \\
\hline & ABDC & BCAD & CDBA & DACB & Total \\
\hline & $n=14$ & $n=14$ & $n=14$ & $n=14$ & $n=56$ \\
\hline Age, years (mean [SD]) & $32.7(8.4 I)$ & $30.8(10.16)$ & $31.0(8.52)$ & $29.5(8.75)$ & $31.0(8.82)$ \\
\hline \multicolumn{6}{|l|}{$\operatorname{Sex}(n[\%])$} \\
\hline Female & $5(35.70)$ & $6(42.90)$ & $7(50.00)$ & $6(42.90)$ & $24(42.90)$ \\
\hline Male & $9(64.30)$ & $8(57.10)$ & $7(50.00)$ & $8(57.10)$ & $32(57.10)$ \\
\hline Height, cm (mean [SD]) & $169.2(8.99)$ & I68.I (8.43) & $168.9(9.15)$ & $174.0(10.22)$ & $170.0(9.26)$ \\
\hline Weight, kg (mean [SD]) & $76.2(8.64)$ & $72.5(9.93)$ & $72.0(I I .60)$ & $79.9(16.68)$ & $75.2(\mid 2.2 I)$ \\
\hline Body mass index (mean $[S D]$ ) & $26.7(2.77)$ & $25.7(3.03)$ & $25.2(3.34)$ & $26.3(4.19)$ & $25.9(3.33)$ \\
\hline
\end{tabular}

Abbreviations: A, regimen A: APF530 I g SC (granisetron $20 \mathrm{mg} / 0.84 \mathrm{~mL}$ plus matching IV and PO placebos); B, regimen B: granisetron IV (50 $\mu \mathrm{g} / \mathrm{kg}$ in $10 \mathrm{~mL}$ of $0.9 \% \mathrm{normal}$ saline plus matching SC and PO placebos); C, regimen C: placebo (SC, IV, and PO placebos); D, moxifloxacin $400 \mathrm{mg}$ PO (plus matching SC and IV placebos); SD, standard deviation. PO, oral; SC, subcutaneous; IV, intravenous.
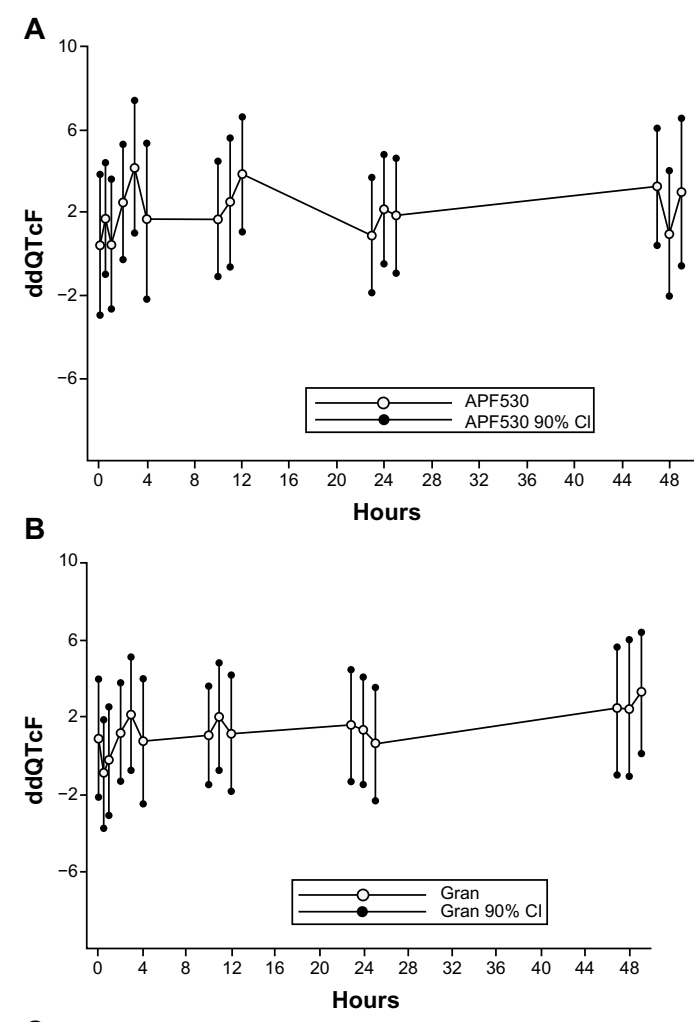

C

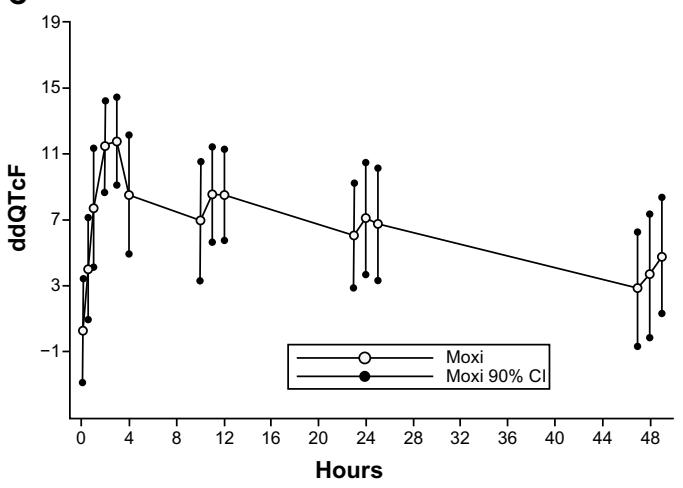

Figure 2 Effect of (A) APF530 given subcutaneously, (B) granisetron (gran) given intravenously, and (C) moxifloxacin (moxi) on QTc (maximum observed mean change; ddQTcF).

Abbreviations: $\mathrm{Cl}$, confidence interval; ddQTcF, baseline and placebo-adjusted change in QT interval corrected by Fridericia method. mixed-effects model of the ddQTcF and granisetron plasma concentration relationship had a nearly flat, nonsignificant negative slope $(-0.1326 \mathrm{msec} /[\mathrm{ng} / \mathrm{mL}])$, supporting the absence of a clinically significant effect of granisetron on QTc. Comparison of APF530 $1 \mathrm{~g} \mathrm{SC}$ and placebo showed similar categorical levels of QTcF and changes in QTcF. The changes in ddQTcF and $90 \% \mathrm{CI}$ for APF530 SC, granisetron $\mathrm{IV}$, and moxifloxacin $\mathrm{PO}$ at specific time points using the mixed-effects model are shown in Table 2.

Similarly, after the delivery of IV granisetron, no clinically significant effect on QTcF was found. The maximum observed mean ddQTcF during treatment was $3.23 \mathrm{~ms}$ ( $90 \% \mathrm{CI}, 0.12$ to 6.33 ) at Hour 49 (Figure 2B). The maximum adjusted mean change (mixed-effects model) occurred at Hour 3 and was $1.91 \mathrm{~ms}$ (90\% CI, -1.22 to 5.04). Categorical QTcF frequencies and change frequencies for IV granisetron were similar to those for placebo.

For moxifloxacin, both the maximum observed mean ddQTcF of $11.72 \mathrm{~ms}(90 \% \mathrm{CI}, 9.12$ to 14.32$)$ and the maximum adjusted mean change (mixed-effects model) of $11.56 \mathrm{~ms}(90 \% \mathrm{CI}, 8.42$ to 14.69$)$ occurred during Hour 3 (Figure 2C). These data indicate that assay sensitivity was adequate, as the adjusted lower $90 \% \mathrm{CI}$ was $>5 \mathrm{~ms}$ during the post-dose time points of 2, 3, 4, 11, and 12 hours.

An analysis of change in QTcF from baseline over time found that QTcF increased in all four treatment arms between 47 and 49 hours after treatment. However, this increase did not appear to be study drug related, as plasma concentrations of each agent were not at their peak values, having decreased from a peak of $34.1 \mathrm{ng} / \mathrm{mL}$ to $11.62 \mathrm{ng} / \mathrm{mL}$ for granisetron during APF530 SC treatment; from $8.9 \mathrm{ng} / \mathrm{mL}$ to $0.73 \mathrm{ng} / \mathrm{mL}$ for granisetron IV, and from $1,740 \mathrm{ng} / \mathrm{mL}$ to $117 \mathrm{ng} / \mathrm{mL}$ for moxifloxacin.

Baseline-adjusted and placebo-adjusted HR (ddHR), PR (ddPR), and QRS (ddQRS) are shown in Table 3. 
Table 2 Change in ddQTcF and 90\% confidence intervals for active treatments over time (mixed-effects model)

\begin{tabular}{|c|c|c|c|c|c|c|c|c|c|}
\hline \multirow[t]{2}{*}{$\begin{array}{l}\text { Time point } \\
(\mathrm{N}=5 \mathrm{I})\end{array}$} & \multicolumn{3}{|c|}{$\begin{array}{l}\text { APF530 I g SC } \\
\text { (20 mg of granisetron) }\end{array}$} & \multicolumn{3}{|c|}{ Granisetron $50 \mu \mathrm{g} / \mathrm{kg}$ IV } & \multicolumn{3}{|c|}{ Moxifloxacin 400 mg PO } \\
\hline & ddQTcF & $90 \%$ LB & $90 \%$ UB & ddQTcF & $90 \%$ LB & $90 \%$ UB & ddQTcF & $90 \%$ LB & $90 \%$ UB \\
\hline I hour & 0.02 & -3.13 & 3.16 & -0.50 & -3.64 & 2.63 & 7.46 & 4.32 & 10.59 \\
\hline 3 hours & 3.75 & 0.61 & 6.89 & 1.91 & -1.22 & 5.04 & 11.56 & 8.42 & 14.69 \\
\hline 12 hours & 3.56 & $0.4 \mathrm{I}$ & 6.70 & 0.98 & -2.15 & 4.12 & 8.42 & 5.29 & 11.56 \\
\hline 24 hours & 2.06 & -1.09 & 5.20 & 1.26 & -1.87 & 4.40 & 7.07 & 3.94 & 10.20 \\
\hline 48 hours & 0.78 & -2.36 & 3.93 & 2.37 & -0.77 & 5.50 & 3.46 & 0.33 & 6.60 \\
\hline
\end{tabular}

Abbreviations: ddQTcF, baseline- and placebo-adjusted change in QTcF; IV, intravenous; LB, lower confidence boundary; PO, oral; QTcF, QT interval corrected by Fridericia method; SC, subcutaneous; UB, upper confidence boundary.

ddHR decreased slightly at most time points during APF530 and IV granisetron treatments and increased slightly at most time points during moxifloxacin treatment. Although many of these changes were statistically significant, none was clinically significant, and the extent of change (less than an absolute mean of 3.5 beats/minute at all time points) would not be expected to confound heart-rate correction of QT values. Heart-rate changes induced by granisetron and moxifloxacin have not been reported in the literature. ddPR was positive at most time points for all three treatments. Mean absolute changes were clinically insignificant at $<3.5 \mathrm{~ms}$ at all time points. ddQRS was positive at most time points in the APF530 arm, and negative at most time points in the other two arms. The absolute mean changes were $<1.5 \mathrm{~ms}$ at all time points and were clinically insignificant.
Other cardiac assessments included non-normal diagnostic statements, including ST segment and T-wave morphology changes. Twelve abnormalities were detected during the study: sinus tachycardia, sinus bradycardia, nonspecific T-wave abnormality, nonspecific ST depression, first-degree atrioventricular block, premature ventricular complexes, premature atrial complexes, premature ectopic complexes, intraventricular conduction delay, long QT interval, significant ventricular arrhythmia, and right axis deviation. There was no imbalance in the frequency of these diagnostic abnormalities among the treatments. The most frequent abnormal rhythm was sinus bradycardia, occurring in an average of $32 \%$ of subjects per time point, with minor variation among the treatments (APF530 SC, 32.2\%; granisetron IV, 33.6\%; placebo, 32.6\%; and moxifloxacin, 29.7\%).

Table 3 Change in ddHR, ddPR, and ddQRS and 95\% confidence intervals for active treatments over time

\begin{tabular}{|c|c|c|c|c|c|c|c|c|c|}
\hline \multirow[t]{2}{*}{$\begin{array}{l}\text { Time point } \\
(\mathrm{N}=5 \mathrm{I})\end{array}$} & \multicolumn{3}{|c|}{$\begin{array}{l}\text { APF530 I g SC } \\
\text { (20 mg of granisetron) }\end{array}$} & \multicolumn{3}{|c|}{ Granisetron $50 \mu \mathrm{g} / \mathrm{kg}$ IV } & \multicolumn{3}{|c|}{ Moxifloxacin 400 mg PO } \\
\hline & Variable & $95 \%$ LB & $95 \%$ UB & Variable & $95 \%$ LB & $95 \%$ UB & Variable & $95 \%$ LB & $95 \%$ UB \\
\hline & ddHR & & & ddHR & & & ddHR & & \\
\hline I hour & -2.00 & -4.28 & 0.28 & -2.54 & -5.09 & 0.01 & 2.23 & -0.96 & 5.42 \\
\hline 3 hours & -0.36 & -2.02 & 1.30 & -1.65 & -3.77 & 0.47 & 0.52 & -1.76 & 2.79 \\
\hline 12 hours & -1.11 & -2.70 & 0.47 & -3.16 & -5.50 & -0.82 & 1.13 & $-0.7 \mid$ & 2.97 \\
\hline 24 hours & 0.01 & -1.83 & 1.85 & -1.14 & -3.60 & 1.32 & -0.12 & -2.37 & 2.13 \\
\hline \multirow[t]{2}{*}{48 hours } & -3.09 & -5.03 & -1.16 & -2.93 & -5.14 & $-0.7 \mid$ & -0.49 & -2.83 & 1.85 \\
\hline & ddPR & & & ddPR & & & ddPR & & \\
\hline I hour & -0.39 & -2.74 & 1.96 & 0.01 & -2.65 & 2.67 & 1.06 & -2.15 & 4.27 \\
\hline 3 hours & 0.50 & -2.22 & 3.23 & 0.05 & -3.45 & 3.55 & -1.86 & -5.64 & 1.93 \\
\hline 12 hours & -1.19 & -3.76 & 1.38 & 0.43 & -3.33 & 4.19 & 0.35 & -1.87 & 2.56 \\
\hline 24 hours & 0.39 & -2.25 & 3.02 & 1.86 & -1.36 & 5.07 & 2.14 & -0.37 & 4.65 \\
\hline \multirow[t]{2}{*}{48 hours } & -2.24 & -5.62 & 1.15 & 0.26 & -3.59 & 4.11 & 0.46 & -2.70 & 3.62 \\
\hline & ddQRS & & & ddQRS & & & ddQRS & & \\
\hline I hour & 0.57 & -1.23 & 2.37 & -0.48 & -2.00 & 1.04 & -0.47 & -2.01 & 1.07 \\
\hline 3 hours & 0.13 & -1.69 & 1.95 & -1.11 & $-2.6 \mathrm{I}$ & 0.38 & -1.00 & -2.57 & 0.57 \\
\hline 12 hours & 0.49 & -1.06 & 2.04 & -0.48 & -2.03 & 1.06 & -0.43 & -2.10 & 1.23 \\
\hline 24 hours & 0.63 & -1.12 & 2.39 & -0.48 & -2.02 & 1.05 & -0.07 & $-|.3|$ & 1.17 \\
\hline 48 hours & -0.12 & -1.59 & 1.34 & -0.86 & -2.31 & 0.58 & -0.12 & -1.74 & 1.49 \\
\hline
\end{tabular}

Abbreviations: $d d H R$, baseline- and placebo-adjusted change in heart rate; ddPR, baseline- and placebo-adjusted change in PR; ddQRS, baseline- and placebo-adjusted change in QRS; IV, intravenous; LB, lower confidence boundary; PO, oral; SC, subcutaneous; UB, upper confidence boundary. 
Nonspecific T-wave abnormality occurred after each treatment (APF530 SC, $n=10$; granisetron IV, $n=9$; placebo, $\mathrm{n}=9$; moxifloxacin PO, $\mathrm{n}=18$ ). Although this was most frequently detected after moxifloxacin treatment, the increase was determined to be nonsignificant based on contingency table analysis (chi square $=5.03$; degrees of freedom $[d f]$ $=3 ; P=0.1696$ ). Nonspecific ST depression occurred only after placebo treatment $(n=5$; chi square $=15.02 ; d f=3$; $P=0.0018)$.

\section{Pharmacokinetics}

Pharmacokinetic parameters for APF530 SC, granisetron IV, and moxifloxacin PO are presented in Table 4. APF530 $\mathrm{SC}$ was gradually absorbed, with a $\mathrm{C}_{\max }$ of $35.8 \mathrm{ng} / \mathrm{mL}$ and a median time to $\mathrm{C}_{\max }\left(\mathrm{t}_{\max }\right)$ of 11.1 hours. Elimination of APF530 was also slow; the mean elimination half-life $\left(\mathrm{t}_{1 / 2}\right)$ was 18.6 hours, mean systemic clearance $(\mathrm{CL} / \mathrm{F})$ was $20.2 \mathrm{~L} / \mathrm{h}$, and mean volume of distribution during the terminal phase $(\mathrm{Vz} / \mathrm{F})$ was $526 \mathrm{~L}$ (Table 4$)$. Note that individual $\mathrm{t}_{1 / 2}$ values could be reliably estimated for only 31 of the 56 subjects because the sampling interval extended only to 49 hours;

Table 4 Summary of pharmacokinetic parameters of granisetron (SC and IV) and moxifloxacin PO in plasma

\begin{tabular}{|c|c|c|c|}
\hline Parameter & $\begin{array}{l}\text { APF530 Ig SC } \\
\text { (20 mg of } \\
\text { granisetron) }\end{array}$ & $\begin{array}{l}\text { Granisetron } \\
50 \mu \mathrm{g} / \mathrm{kg} \text { IV }\end{array}$ & $\begin{array}{l}\text { Moxifloxacin } \\
400 \mathrm{mg} \text { PO }\end{array}$ \\
\hline $\begin{array}{l}C_{\max }, n g / m L \\
\text { mean (SD) }\end{array}$ & $\begin{array}{l}n=56 \\
35.8(13.3)\end{array}$ & $\begin{array}{l}n=52 \\
34.6(I 5.3)\end{array}$ & $\begin{array}{l}n=53 \\
2,123(502)\end{array}$ \\
\hline $\begin{array}{l}\mathrm{t}_{\max }, \mathrm{h} \\
\text { median } \\
(\min , \max )\end{array}$ & $\begin{array}{l}n=56 \\
I I . I(4 . I, 23 . I)\end{array}$ & $\begin{array}{l}n=52 \\
0.183(0.167,4.15)\end{array}$ & $\begin{array}{l}n=53 \\
2.08(0.583,4.08)\end{array}$ \\
\hline $\begin{array}{l}t_{1 / 2}, h \\
\text { mean (SD) }\end{array}$ & $\begin{array}{l}n=31 \\
18.6(4.02)\end{array}$ & $\begin{array}{l}n=49 \\
9.69(3.53)\end{array}$ & $\begin{array}{l}n=49 \\
13.8(1.65)\end{array}$ \\
\hline $\begin{array}{l}\mathrm{CL} / \mathrm{F}^{\mathrm{a}}, \mathrm{L} / \mathrm{h} \\
\text { mean }(\mathrm{SD})\end{array}$ & $\begin{array}{l}\mathrm{n}=30 \\
20.2(11.7)\end{array}$ & $\begin{array}{l}n=49 \\
13.8(10.1)\end{array}$ & $\begin{array}{l}\mathrm{n}=49 \\
12.9(2.47)\end{array}$ \\
\hline $\begin{array}{l}\mathrm{Vz} / \mathrm{F}, \mathrm{L} \\
\text { mean (SD) }\end{array}$ & $\begin{array}{l}\mathrm{n}=30 \\
526(320)\end{array}$ & $\begin{array}{l}\mathrm{n}=49 \\
\mathrm{I} 56(44.2)\end{array}$ & $\begin{array}{l}n=49 \\
257(60.3)\end{array}$ \\
\hline $\begin{array}{l}\text { AUC, } \mathbf{n g} \cdot \mathbf{h} / \mathrm{r} \\
\text { mean (SD) }\end{array}$ & & & \\
\hline$A \cup C_{(0-12)}$ & $\begin{array}{l}n=56 \\
294(10 I)\end{array}$ & $\begin{array}{l}n=52 \\
212(64.0)\end{array}$ & $\begin{array}{l}n=53 \\
\mid 5,743(3,6 \mid 2)\end{array}$ \\
\hline $\mathrm{AUC}_{(0-24)}$ & $\begin{array}{l}n=56 \\
640(226)\end{array}$ & $\begin{array}{l}n=52 \\
289(100)\end{array}$ & $\begin{array}{l}n=53 \\
23,467(5,235)\end{array}$ \\
\hline $\mathrm{AUC}_{(0-48)}$ & $\begin{array}{l}\mathrm{n}=56 \\
\mathrm{I}, 078(380)\end{array}$ & $\begin{array}{l}n=52 \\
343(134)\end{array}$ & $\begin{array}{l}n=53 \\
29,647(6,32 I)\end{array}$ \\
\hline$A \cup C_{(0-\text { inf })}$ & $\begin{array}{l}\mathrm{n}=30 \\
\mathrm{I}, 254(578)\end{array}$ & $\begin{array}{l}n=49 \\
353(153)\end{array}$ & $\begin{array}{l}n=49 \\
32,143(6,568)\end{array}$ \\
\hline
\end{tabular}

Note: aParameters for granisetron IV administration were $\mathrm{CL}$ and $\mathrm{Vz}$. Abbreviations: AUC, area under the plasma concentration-time curve; CL/F, systemic clearance; $C_{m a x}$, maximum plasma concentration; IV, intravenous; PO, oral; SC, subcutaneous; SD, standard deviation; $t_{\max }$, time to maximum plasma concentration; $t_{1 / 2}$, elimination half-life; $V z / F$, volume of distribution during the terminal phase. thus, the mean $\mathrm{t}_{1 / 2}$ reported might be an underestimate of the elimination $\mathrm{t}_{1 / 2}$ of granisetron after $\mathrm{SC}$ administration via APF530. The $\mathrm{C}_{\text {max }}$ of granisetron achieved when administered by APF530 $1 \mathrm{~g}$ SC and of granisetron $50 \mu \mathrm{g} / \mathrm{kg}$ IV was twice the $\mathrm{C}_{\max }$ measured in patients who had received APF530 $500 \mathrm{mg}(17.8 \mathrm{ng} / \mathrm{mL})^{29}$ (Figure 3).

Granisetron $50 \mu \mathrm{g} / \mathrm{kg}$ IV was rapidly absorbed, with a median $\mathrm{t}_{\max }$ of 0.183 hour and a mean $\mathrm{C}_{\max }$ of $34.6 \mathrm{ng} / \mathrm{mL}$, and was readily eliminated, with a $\mathrm{t}_{1 / 2}$ of 9.69 hours, mean CL of $13.8 \mathrm{~L} / \mathrm{h}$, and mean Vz of $156 \mathrm{~L}$ (Figure 3 ).

Moxifloxacin had a median $\mathrm{t}_{\max }$ of 2.08 hours and a mean $\mathrm{C}_{\max }$ of $2123 \mathrm{ng} / \mathrm{mL}$, after which the concentration of moxifloxacin declined steadily (CL/F, 12.9 L/h; Vz, 257 L).

\section{Safety}

All 56 subjects (100\%) received APF530 SC, 52 subjects (93\%) received granisetron IV, 53 subjects (95\%) received moxifloxacin, and 51 subjects (91\%) received placebo. Excluding injection-site reactions, AEs were similar across the APF530 SC ( $n=16$ [29\%]), moxifloxacin PO $(n=16$ [30\%]), and placebo $(n=17$ [33\%]) arms. The lowest number of subjects reporting AEs was in the granisetron IV arm $(\mathrm{n}=12[23 \%])$. The most common AEs were constipation (APF530 SC, $\mathrm{n}=9$ [16.1\%]; granisetron IV, $\mathrm{n}=5$ [9.6\%]; moxifloxacin PO, $\mathrm{n}=3[5.7 \%]$ ) and headache (granisetron IV, $n=5$ [9.6\%]; placebo $n=7$ [13.7\%]). The majority of AEs were mild, and none was considered definitely related to treatment. Only two AEs were moderate in severity: constipation (six events) and upper abdominal pain (one event). Constipation was the only AE considered probably related to treatment. No deaths or serious AEs were reported. Excluding injection-site reactions, two subjects were withdrawn from the study because of an AE: one after receiving APF530 SC (constipation) and one after receiving moxifloxacin (mild diarrhea, mild upper respiratory tract infection, mild vomiting).

Injection-site AEs were all reported as mild in severity during the study and were noted for both APF530 SC ( $n=47$ [84\%]) and placebo SC (22\%-32\% across the placebo arms). The most frequently reported injection-site reactions after APF530 SC administration were induration (55\% of subjects), nodules (52\%), and hematoma (43\%), all of which resolved over time. One subject discontinued the study because of an injection-site reaction (pain, induration, bruising, erysipelas infection, and nodule) that resolved without sequelae. No treatment-related trends were observed in physical examination, clinical laboratory evaluations, and other ECG recordings. 
Linear scale

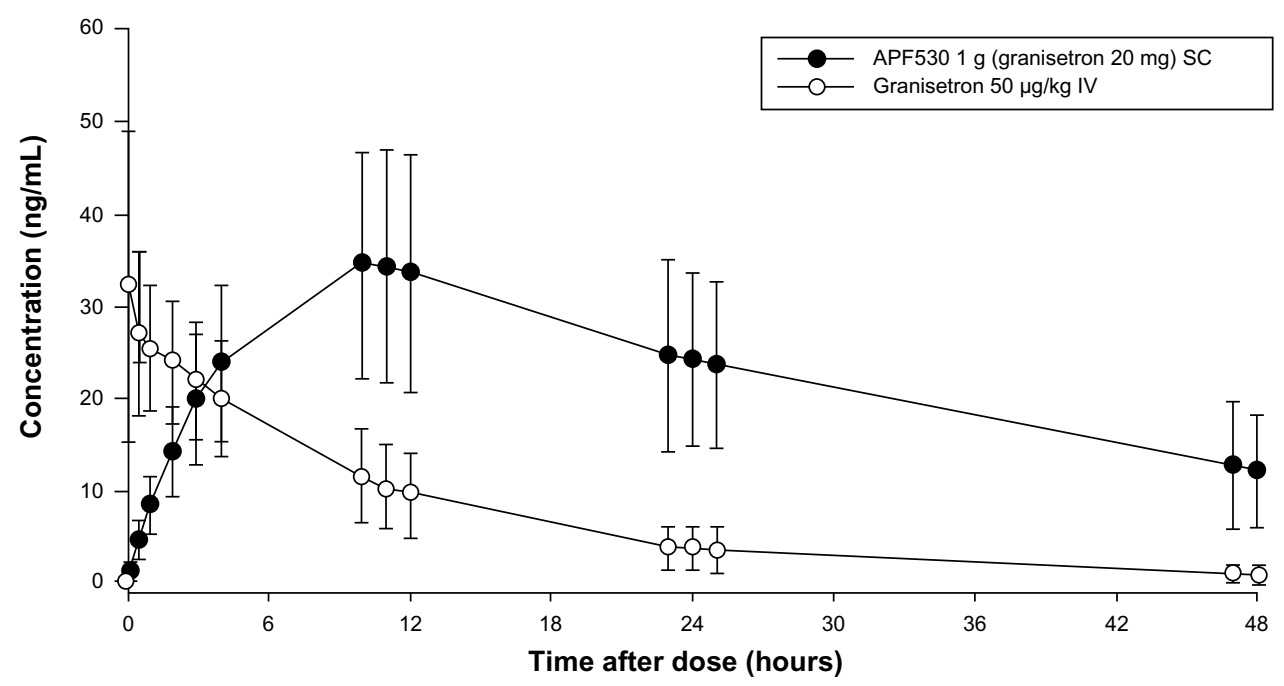

Figure 3 Mean (standard deviation) plasma concentrations of APF530 I g (20 mg of granisetron) given subcutaneously (SC) and granisetron $50 \mu \mathrm{g} / \mathrm{kg}$ given intravenously (IV).

\section{Discussion}

This Phase I study investigated the effects of APF530 $1 \mathrm{~g}$ SC (20 mg of granisetron) on healthy individuals to determine whether this dose (twice the recommended dose) would affect QTe interval. This thorough QTe study indicates that both SC and IV formulations of granisetron have no clinically significant effect on the QTc interval at supratherapeutic concentrations. For comparison, therapeutic concentrations of $4.95 \mathrm{ng} / \mathrm{mL}$ and $5.99 \mathrm{ng} / \mathrm{mL}$ have been reported with the recommended doses of granisetron IV $(10 \mu \mathrm{g} / \mathrm{kg})$ and PO (2 mg daily), respectively. ${ }^{7,82}$ In addition, there were no clinically significant changes in HR, PR, and QRS with APF530 $1 \mathrm{~g} \mathrm{SC}$.

Pharmacokinetic data revealed slower absorption and elimination of granisetron when administered SC compared with IV. In addition, for APF530 $1 \mathrm{~g} \mathrm{SC}$ (20 mg of granisetron) in this study, mean AUC was lower $\left(\mathrm{AUC}_{(0-\text { inf }} 1254\right.$ $\mathrm{ng} \cdot \mathrm{h} / \mathrm{mL}$ vs $\left.\mathrm{AUC}_{(0-\text { inf })} 1684 \mathrm{ng} \cdot \mathrm{h} / \mathrm{mL}\right)$ and mean $\mathrm{C}_{\max }$ was lower $(35.8 \mathrm{ng} / \mathrm{mL}$ vs $37.1 \mathrm{ng} / \mathrm{mL})$, respectively, compared with values from a previous pharmacokinetic study of APF530 $1 \mathrm{~g} \mathrm{SC}$ (20 mg of granisetron) in healthy subjects (data on file). Various factors, including patient population, selection of time points, and individual clearance variability, may explain pharmacokinetic differences between this study and the previous study in healthy subjects. AEs were generally mild and quickly resolved; the most common AEs were constipation and SC injection-site reactions.

In October 2009, labeling of granisetron (Kytril; Roche Laboratories, Basel, Switzerland) was changed to include a warning for precautionary use in patients potentially vulnerable to QT prolongation. ${ }^{14}$ This thorough QT study and the previous study of transdermally administered granisetron ${ }^{24}$ demonstrate that the avoidance of the plasma concentration peaks, which may be associated with IV and PO granisetron administration, by the prolonged exposure to lower plasma concentrations achieved with sustainedrelease preparations effectively prevents QT prolongation by granisetron. Both studies suggested that plasma concentrations considerably higher than those achieved by sustained release would also minimally affect the QTc interval and have no clinically significant effects on HR, PR, or QRS. Since other 5- $\mathrm{HT}_{3}$ antagonists have been associated with QT prolongation in clinical use, ${ }^{6,9-13,16,17}$ as well as PR and QRS prolongation, ${ }^{12}$ sustained-release granisetron may be the safest choice for control of CINV in patients more susceptible to QT prolongation.

\section{Conclusion}

This thorough QTc study demonstrated that APF530 $1 \mathrm{~g} \mathrm{SC}$ (twice the recommended dose of APF530 SC $500 \mathrm{mg}$ ) did not induce QT prolongation at approximately seven-fold the usual plasma concentration achieved with IV or PO granisetron at the recommended doses, and had no other ECG effects.

\section{Acknowledgments}

The authors would like to thank the investigators, their patients, along with their clinical staff who made this study possible. The authors would also like to thank Yvonne Yarker, PhD, CMPP (SciStrategy Communications) for 
medical writing assistance in the development of the manuscript. Research and manuscript support was provided by AP Pharma, Inc.

\section{Disclosure}

This paper was previously presented in part as: Mason J, Moon TE, O’Boyle E, Dietz AJ Jr. Comparison of the effects of subcutaneous APF530, intravenous granisetron, moxifloxacin, and placebo on the QT interval in humans.

J Clin Oncol. 2013;31(Suppl):abstr e20539.

This study was sponsored by AP Pharma, Inc.

Erin O'Boyle is an employee of AP Pharma, Inc.; Jay W Mason, Thomas E Moon, and Albert Dietz declare no conflicts of interest in this work.

\section{References}

1. Roscoe JA, Morrow GR, Colagiuri B, et al. Insight in the prediction of chemotherapy-induced nausea. Support Care Cancer. 2010;18(7): 869-876.

2. Hesketh PJ, Gandara DR. Serotonin antagonists: a new class of antiemetic agents. J Natl Cancer Inst. 1991;83(9):613-620.

3. National Comprehensive Cancer Network (NCCN). NCCN Clinical Practice Guidelines in Oncology: Antiemesis. v 1.2014. Fort Washington, PA: NCCN; 2013. Available from: http://www.ncen.org/ professionals/physician_gls/pdf/antiemesis.pdf.

4. Roila F, Herrstedt J, Aapro M, et al; ESMO/MASCC Guidelines Working Group. Guideline update for MASCC and ESMO in the prevention of chemotherapy- and radiotherapy-induced nausea and vomiting: results of the Perugia consensus conference. Ann Oncol. 2010;21 Suppl 5:v232-v243.

5. Basch E, Prestrud AA, Hesketh PJ, et al; American Society of Clinical Oncology. Antiemetics: American Society of Clinical Oncology clinical practice guideline update. J Clin Oncol. 2011;29(31):4189-4198.

6. Kuryshev YA, Brown AM, Wang L, Benedict CR, Rampe D. Interactions of the 5-hydroxytryptamine 3 antagonist class of antiemetic drugs with human cardiac ion channels. J Pharmacol Exp Ther. 2000;295(2): $614-620$

7. Kytril (granisetron hydrochloride) tablets oral solution [prescribing information]. Nutley, NJ: Roche Pharmaceuticals; 2010.

8. Kytril (granisetron hydrochloride) injection [prescribing information]. San Francisco, CA: Genentech, Inc.; 2011.

9. Zofran (ondansetron hydrochloride) injection [prescribing information]. Research Triangle Park, NC: GlaxoSmithKline; 2012.

10. Zofran (ondansetron hydrochloride) tablets [prescribing information]. Research Triangle Park, NC: GlaxoSmithKline; 2011.

11. Anzemet injection (dolasetron mesylate) [prescribing information]. Bridgewater, NJ: Sanofi-Aventis; 2011.

12. Anzemet tablets (dolasetron mesylate) [prescribing information]. Bridgewater, NJ: Sanofi-Aventis; 2011.

13. US Food and Drug Administration (FDA). FDA drug safety communication: abnormal heart rhythms associated with use of Anzemet (dolasetron mesylate) [web page on the Internet]. Silver Spring, MD: FDA; 2010 [updated December 22, 2010]. Available from: http://www. fda.gov/Drugs/DrugSafety/ucm237081.htm. Accessed February 28, 2014.

14. FDA. Safety: Kytril (granisetron hydrochloride) injection, tablets and oral solution [web page on the Internet]. Silver Spring, MD: FDA; 2009 [updated October 21, 2009]. Available from: http://www.fda. gov/Safety/MedWatch/SafetyInformation/ucm187526.htm. Accessed February 28, 2014.
15. FDA. FDA drug safety communication: abnormal heart rhythms may be associated with use of Zofran (ondansetron) [web page on the Internet]. Silver Spring, MD: FDA; 2011 [updated June 29, 2012]. Available from: http://www.fda.gov/Drugs/DrugSafety/ucm271913. htm. Accessed February 28, 2014.

16. FDA. FDA drug safety communication: updated information on $32 \mathrm{mg}$ intravenous ondansetron (Zofran) dose and pre-mixed ondansetron products [web page on the Internet]. Silver Spring, MD: FDA; 2012 [updated December 6, 2012]. Available from: http://www.fda.gov/ Drugs/DrugSafety/ucm330049.htm. Accessed February 28, 2014.

17. Aloxi (palonosetron $\mathrm{HCl}$ ) injection [prescribing information]. Woodcliff Lake, NJ: Eisai Pharmaceuticals; 2008.

18. Aapro M, Bourke JP. Rapid intravenous administration of granisetron prior to chemotherapy is not arythmogenic: results of a pilot study. Eur J Cancer. 2003;39(7):927-931.

19. Carmichael J, Philip PA, Forfar C, Harris AL. An open study to assess the safety, tolerance and pharmacokinetics of an intravenous infusion of granisetron given at $3 \mathrm{mg}$ over $30 \mathrm{~s}$ in patients receiving chemotherapy for malignant disease. Cancer Chemother Pharmacol. 1995;37(1-2): 134-138.

20. Carmichael J, Harris AL. The cardiovascular safety of high-dose intravenous granisetron in cancer patients receiving highly emetogenic chemotherapy. Cancer Chemother Pharmacol. 2004;53(2):123-128.

21. Jantunen IT, Kataja VV, Muhonen TT, Parviainen T. Effects of granisetron with doxorubicin or epirubicin on ECG intervals. Cancer Chemother Pharmacol. 1996;37(5):502-504.

22. Upward JW, Arnold BD, Link C, Pierce DM, Allen A, Tasker TC. The clinical pharmacology of granisetron (BRL 43694), a novel specific 5-HT3 antagonist. Eur J Cancer. 1990;26 Suppl 1:S12-S15.

23. Friedman CJ, Burris HA 3rd, Yocom K, Blackburn LM, Gruben D. Oral granisetron for the prevention of acute late onset nausea and vomiting in patients treated with moderately emetogenic chemotherapy. Oncologist. 2000;5(2):136-143.

24. Mason JW, Selness DS, Moon TE, O’Mahony B, Donachie P, Howell J. Pharmacokinetics and repolarization effects of intravenous and transdermal granisetron. Clin Cancer Res. 2012;18(10):2913-2921.

25. Grous J, Riegel E, Gabrail N, et al. Phase III study of sustained release granisetron (APF530) compared to palonosetron for the prevention of chemotherapy-induced nausea and vomiting (CINV). J Clin Oncol. 2009;27(Suppl):abstr 9627.

26. US Department of Health and Human Services, FDA, Center for Drug Evaluation and Research (CDER), Center for Biologics Evaluation and Research (CBER). Guidance for Industry: E14 Clinical Evaluation of QT/QTc Interval Prolongation and Proarrhythmic Potential for Non-Antiarrhythmic Drugs. Rockville, MD: US Department of Health and Human Services, FDA, CDER, CBER; 2005. Available from: http://www.fda.gov/downloads/RegulatoryInformation/Guidances/ ucm129357.pdf. Accessed February 28, 2014.

27. International Conference on Harmonization. Guidance for Industry: E6 Good Clinical Practice: Consolidated Guidance; 2006. Available from: http://www.fda.gov/downloads/Drugs/GuidanceComplianceRegulatoryInformation/Guidances/UCM073122.pdf. Accessed March 17, 2014.

28. World Medical Association (WMA). WMA Declaration of Helsinki Ethical Principles for Medical Research Involving Human Subjects. Ferney-Voltaire: WMA; 2008. Available from: http://www.wma.net/ en/30publications/10policies/b3/. Accessed February 28, 2014.

29. Gabrail N, Yanagihara RH, Cooper W, et al. Pharmacokinetics (PK), tolerability, and efficacy of APF530 in patients receiving moderately (MEC) and highly (HEC) emetogenic chemotherapy: Phase II trial results. J Clin Oncol. 2013;31(Suppl):abstr e20518. 


\section{Publish your work in this journal}

Cancer Management and Research is an international, peer-reviewed open access journal focusing on cancer research and the optimal use of preventative and integrated treatment interventions to achieve improved outcomes, enhanced survival and quality of life for the cancer patient. The journal welcomes original research, clinical \& epidemiological

studies, reviews \& evaluations, guidelines, expert opinion \& commentary, case reports \& extended reports. The manuscript management system is completely online and includes a very quick and fair peerreview system, which is all easy to use. Visit http://www.dovepress.com/ testimonials.php to read real quotes from published authors.

Submit your manuscript here: http://www.dovepress.com/cancer-management-and-research-journal 